NASA Technical Memorandum 84362

NASA-TM-84362 19830018647

\title{
Aerodynamic Characteristics of Generalized Bent Biconic Bodies for Aero-Assisted Orbital-Transfer Vehicles
}

\section{Carol B. Davies and Chul Park}

May 1983

\author{
LIBRARY GOPY \\ JUN 81983 \\ LANGLEY RESEARCH CENTER \\ LIBRARY, NASA \\ HAMPTON, VIRGINIA
}


NASA Technical Memorandum 84362

\section{Aerodynamic Characteristics of Generalized Bent Biconic Bodies for Aero-Assisted Orbital-Transfer Vehicles}

Carol B. Davies, Informatics General Corporation, Palo Alto, California

Chul Park, Ames Research Center, Moffett Field, California

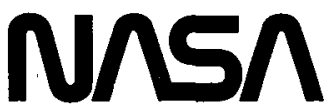

National Aeronautics and

Space Administration

Ames Research Center

Moffett Field, California 94035 
AERODYNAMIC CHARACTERISTICS OF GENERAIIZED BENT BICONIC BODIES FOR AERO-ASSISTED, ORBITAI-TRANSFER VEHICIES

Carol B. Davies*

Informatics General Corporation, Palo Alto, California

and

Chul Parkt

NASA Ames Research Center, Moffett F1eld, California

\section{Abstract}

A method was developed to generate the surface coordinates of body shapes sultable for aeroassisted, orbital-transfer vehicles (AOTVs) by extending bent biconle geometries. Ifft, drag, and longltudinal moments were calculated for the bodles using Newtonian flow theory. These techniques were applied to symmetric and asymetrte aerobraking vehicles, and to an aeromaneuvering vehicle with h1gh $I / D$. Results for aerobraking applications Indicate that a $70^{\circ}$, fore half cone angle with 2 spherlcally blunted nose, rounded edges, and a slight asymetry would be appropriate. Moreover, results show that an aeromaneuvering vehicle w1th $L / D>2.0$, and with suffictent stability, is feasible.

\section{Nomenclature}

$A$

- area projected by body (reference area)

$\mathrm{C}_{\mathrm{d}}$

- drag coeffictent

$\mathrm{C}_{\mathrm{L}} \quad-$ I1ft coeffictent

D - total drag

1 - Index for body surface point

I $\quad=\operatorname{cotal} 11 \mathrm{ft}$

M - metacenter

$\mathrm{N} \quad=$ total moment

$\hat{\mathrm{n}} \quad$ - body normal vector

P $\quad$ - gurface point

p = pressure

$R_{\max } \quad-\operatorname{maximum}$ radius of body

$R_{n} \quad=$ blunt nose radlus

$S_{D}, s_{L}$, moment arms at $P$

$\mathrm{S}_{\mathrm{D}}, \mathrm{S}_{\mathrm{L}} \quad$ average moment arms

$X_{c} \quad=$ proportion of firgt cone length to total body length

*Consultant, Professional Services Operations West (PSOW).

iResearch Scientrat.

This paper is declared a work of the U.S. Government and therefore is in the public domain.

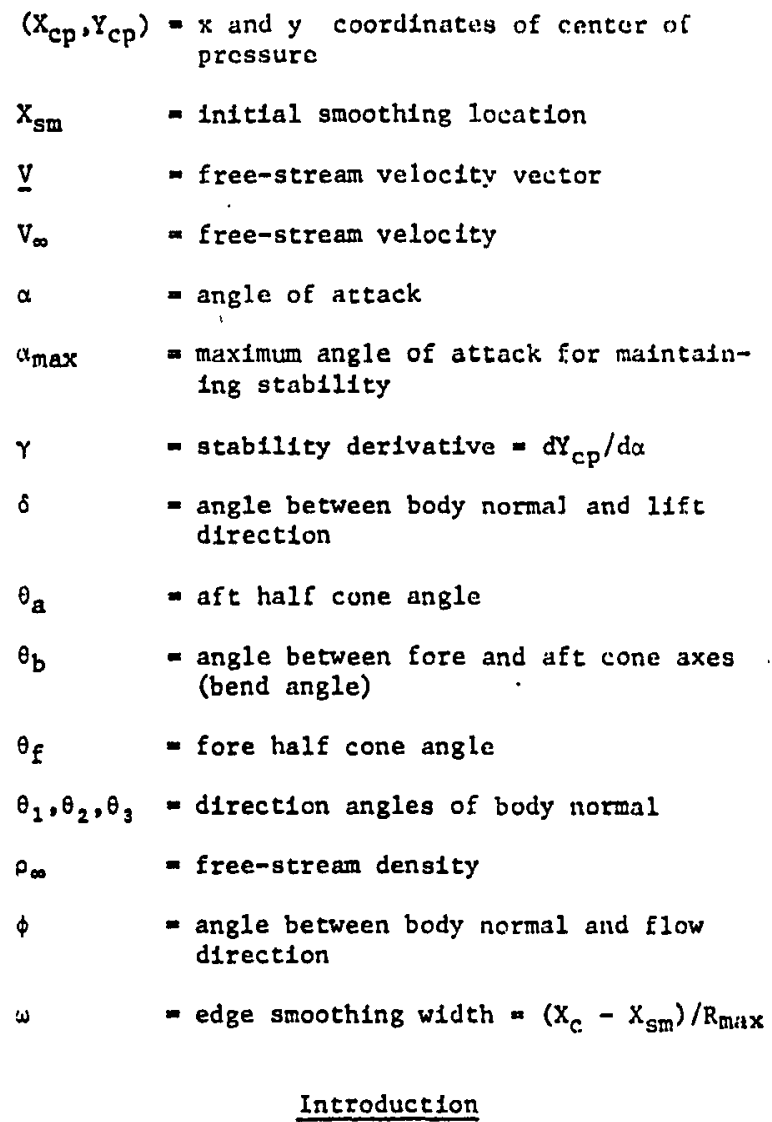

The effectiveness of the Space Shuttle can be enhanced if a new type of vehicle is developed with the ablilty to commute between varlous space sateliftes. The altitude of satellites, or space stations, varies from the current low Earth orb1ts to geosynchronous orb1t. Such orbltal transfer requires a vehicle that is capable of making altitude and synergetic (1.e., inclinational) orbital plane changes. The efficiency of this vehicle could be 1mproved by making use of the Earth's atmosphere for some of 1 ts maneuvering. Such a vehicle is referred to as an aero-assisted. orbital-transfer vehicle (AOTV).' Several destgns have been proposed for a vehicle capable of making orbital altitude changes. For altitude change alone, vehicles with low $I / D$, referred to as aerobraking vehicles, are currently being investgated, 1,2 liowever, for synerget1c plane changes, a more approprlate vehicle would be one with a high $L / D$, which is referred to as an aeromaneuvering vehicle. Little work has been done on the invest 1gation of the aerodynamic characteristics of these bodies. A bent blconic body has been proposed as a compromise to produce a moderately high drag, and a 
moderately hlgh $\mathrm{L} / \mathrm{D}^{3}{ }^{3,4}$ Knowledge of the aerodynamlc characteristics of a vehicle is necessary to make even a preliminary assessment of its mission performance. There is an urgent need to approximately assess a large range of possible geometrles for their aerodynamic characteristics.

The purpose of the present work is to 1) develop a computer program that generates body coordinates and nssoclated body-normal vectors for a class of body geometrles; 2) generate conf1guratlons of body shapes that will have low $L / D$ for orbltal. altitude changes and very high $L / D$ for synerget1c plane changes; and 3 ) produce quick estimates for lift and drag coefficlents, moments, and stablilty margins for these varying shapes.

The work is focused on three types of geometries: 1) a symmetrlc, spherically blunted cone wtth a rounded frustum; 2) an asymmetric sphere cune, also with a rounded frustum; and 3) a low drag, high $L / D$ lllting body. It is necessary to round the frustum for the geometries of 1) and 2) to overcome the very high heat tranyfer rates at the [rustum's edge. ${ }^{5}$ One sertous problem with a symmetric shape is 1 ts lack of roll stabllity. An asymetric body would have positive roll stability; this geometry is also examined in this work. It w1ll be demonstrated that th1s asymetric body can be designed with a sufficient stablilty for a w1de range of angle of attack.

In the past, low drag and high L/D lifting budles have generally been deglgned for terrestrial landing, and have not been conflgured for stowing in the Space Shuttle. The simplest high $L / D$ shape is a flat plate; however, it is not aerodynamically stable. To produce aerodynamic stability, 1t is necessary to have a slight curvature on the lifting surface. Truncating a smoothed, generallzed, bent blconfe will produce such a body shape with high $L / D$ and a curved lifting surface.

\section{Calculation of Body Coordinates}

The basic geometry of a generalized bent biconic is described by five variables. These are the fore half cone angle, $\theta_{f}$; the aft half cone angle, $O$; the angle between the two cone axes (bend angle), $b_{b}$; the proportion of first cone length to total body length, $X_{C}$; and the nose radius, $R_{n}$, of the spherically blunted fore cone. leng,ths are normallzed with respect to the total body length mensured from the apex of the first cone. Figure 1 shows a proftle of a bent biconic with $O_{f}=12.84^{\circ}, U_{a}=7^{\circ}, O_{b}=7^{\circ}, x_{c}=0.6$, and $R_{n}=0.03$. The reference longitudinal axis is chosen to colncide with the fore cone ax1s. Th1s 1s the $x$ axis of the $x-y-z$ coordinate system shown in F18. 1. A body with these dimensions, has been studied experimentally ${ }^{4}$ and theoretically. ${ }^{6}$ " An additional feature of the code used in this study is the abllity to smooth the sharp juncture between the two cones. This is controlled by an additional variable, $x_{s m}$, that defines the location on the $x$-axis where smoothing 13 to begin. The smootlied curve is defined as a fourth order polynomial with no first or third order term and with a continuous second derivative to ensure that the

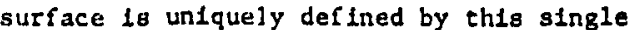
parameter.
These six variables can produce a wide range of body shapes, and some of these examples are seen In Fig. 2. The effect of smoothlng the sharp Juncture can be seen In Fig. 2a. Also shown is the option of truncating the end i the body perpendicular to either cone axis. Figure $2 b$ shows the shape generated by truncating an upper portion of a biconic body. This truncation curve may be of a first or of a second order. The symetric body seen In FIg. 2c is obeained when using a negatIve aft cone angle, a large nose radius, and the smoothing modffication. The dorted line shows the effect of changing the smoothing parameter. In Ffg. 2d a small bend angle has been introduced to produce an asymetric body.

The solution of the equation of the common ellipse at the Intersection plune is the [1rst step In the procedure in obtaining the surface coordinates. The apex of the aft cone and other necessary parameters are then calculated and used for solving the analytical equations that describe the body surface. Flgure 3 is an example showing cross sections at given $x$-stations for a budy with $\theta_{f}=10^{\circ}, 0_{a}=20^{\circ}, v_{b}=15^{\circ}$, and $k_{r}=0.05$. These cross sections are circular along the fure cone, are part circular and part elliptical through the functure area, and are elliptical unt11 the end of the body. After obtaining the body coordinates, the body nomal vector is calculated numerically at each body coordinate.

\section{Aerodynamic Charactertstics}

One of the objectives of this work is to provide a quick and simple method for computing aerodynamic characteristics for a range of body shapes. This Information can then be used to determine the flight performance of the vehicles. The derodynamic characteristics arc presented in terms of 11ft and drag forces. These were chosen to facil1tate flight trajectory calculations and to circumvent the ambiguity of the body reference axis. The transformation from $11 \mathrm{ft}$ and drag forces to normal and actual forces is well knuwn.

As with any atmospher1c flight velifele, in aeromaneuvering AOTV will perform in the same manner as a conventional airplane performs, and therefore the aerodynamic definitions of $11 \mathrm{t} t$. drag, and moment apply. For an derobraking vehicle, the performance criteria depend strunply on the mode of control. To correct for, errors in entry angle, and for the uncertainty of atmospheric density, an aerobraking vehicle must be able to vary elther lift or drag during its flight. The concept of drag modulation has been proposed and 1nvest1gated. ${ }^{7}$ 'o modulate drag, it is necessary to vary body geumetry during [Ifght, the fensibil1ty of which has not yet been demunstrated. In the present work, the alternate concept of lift modulation is pursued. Since control surfaces arc Ineffective for a very blunt body, an diternative method for modulating lift must be found. The present work will Investigate the feastbillty of malntalning the required angle of uttack by incans of adfusting the center of gravity location. Thts adjustment could be performed by a hinge or gimbal motion. The vehicle must be stable at the achieved angle of attack; that $1 \mathrm{~s}$, a moment must be produced that w11l restore the angle of attack to the required value. It is therefore necessary to know 
the stab111ty characteristics of the aerobraking. vehtcle over a wide range of angles of attack. In th1s work, only longitudinal stability will be fully investigated; the inclusion of roll and directional stability is not addressed at this time.

\section{Method of Calculation}

Newtonfan flow theory presents a reasonable approximation for pressure in the high Mach number flows encountered by an AOTV, and 1 it is used in this work. In general, a surface is defined by its normal at every point. The angle between this normal and the direction of the oncoming flow can then be found. Defining this angle at a general surface polnt, 1 , as $\phi_{1}$, the local pressure $p_{1}$ is given by

$$
P_{1}=\rho_{\infty} V_{\infty}^{2} \cos ^{2}\left(\phi_{1}\right)
$$

where $\rho_{\infty}$ is the free-stream density and $V_{\infty}$ is the free-stream velocity. This expression is equivalent to the more famlliar sine-squared formula." Drag, which acts in the direction of the flow, is given by $p_{1} \cos \left(\phi_{1}\right)$, and lift, which acts in the direction normal to the flow, is given by $p_{1} \cos \left(\delta_{1}\right)$, where $\delta$ is the angle between the body normal vector and the lift direction. These angles are more clearly shown in F18. 4a. The body normal vector in this same coordinate system

$$
\hat{\underline{n}}=\cos 0_{1} \underline{1}+\cos \theta_{2} \underline{j}+\cos \theta_{3} \underline{k}
$$

where $\theta_{1}, \theta_{2}$, and $\theta_{3}$ are direction angles with respect to $x, y$, and $z$ axes and are shown $1 n$ Fig. 4b. It should be noted that the directions of pressure, dray, and $11 \mathrm{ft}$ do not lie in the same plane. The integrated pressure, total drag, and total l1ft are obtalned by suming their local values over the surface area that is 1mplnged by the flow. Newtonian flow theory dictates that only the surface area directly wetted by the flow should be Included in the surface integration. A point will be on this windward side if the angle between the flow and the body normal is less than $90^{\circ}$. The drag and ift coefficients are obtained by

$$
c_{d}=2 D / \rho_{\infty} v_{\infty}^{2} A
$$

and

$$
c_{L}=2 L / \rho_{\infty} V_{\infty}^{2} A
$$

where $U$ and $L$ are the total drag and $11 \mathrm{ft}$, and A is the area profected by the body on the $y-z$ plane.

Two cases were run to check the accuracy of the results obtained by using this method. The f1rst was simply to check the code by calculating the drag coefficients of single cones with large nose rad11. An excellent match was obtalned when these were compared with the analytically dertved drag cuefficlents for the same body dimensica. In the second test case, comparisons were made with the experimental results at Mach 6 for the bent blcunic budy shown in Flg. 1." Figure 5 shows drag ind llit cuefflelents versus angle of attack for buth methods. It can be seen that both agree to within dpproximately $5 \%$. The $L / D$ values agree extremely well. The small discrepanctes cin mainly be attributed to the non-Newtondan flow in the experiment. Newtonian flow theory presumes an infinite Mach number and a speciflc heat ratio or 1 , and neglects wall friction. I r quick estimates of the performance of a proposed body, howcver, these slight discrepancies are easily tolerated.

The diagram in Fig. 6 11lustrates the technfque used to compute the lift and drag moments of the body. Each surface point (shown as $P$ in the diagram) is projected on the $x-y$ planc. The moments for this projected line are taken about the systcm origin, where $s_{L}$ is the nument and for lift and $s_{D}$ is the moment arm for drag. The cotal moments are found by summing each local moment over the appropriate body surface area, that 1s, total l1ft moment, $N_{L_{1}}=z_{L_{1}} \Lambda_{1}$, and total drag moment, $N_{D}=\Sigma s_{D_{1}} D_{1}$. The signs of each $s_{L_{1}}$ and $S D_{1}$ must be carefully monitored. The center of pressure $\left(X_{C p}, Y_{C p}\right)$ is found by computing the average arm length by $s_{L}=N_{L} / L$ and $s_{D}=N_{D} / D$. These are then translated into the $x-y$ plane. The computed horizontal center of pressure $\left(\mathrm{X}_{\mathrm{Cp}}\right)$ for each angle of attack is compared with the experfmental results of Ref. 4 , and plotted in F1g. 7. There is a falr agreement between the two sets of data. There 1s a discrepancy, however, that can be attributed partly to the unsultabllity of the Newtonian flow for a body with a sharp juncture point. At such a juncture point, pres.sure transmission within the boundary layer reduces the pressure difference between the two surfaces. Although this phenomenon has a minimal effect on the total lift or drag, it does influence the moments. However, for the smooth gurfaces consldered in the remainder of this work, such discrepancles w1ll be negligible.

The next step is to obtain permissable locatlons for the center of gravity. To do so, the center of pressure is platted for each anyle of attack. The resultant force line of the lift and drag forces that acts at the center of pressure is now drawn. Flgure 8 shows examples of these lines. The point at which the resultant force meets the longitudinal axis is called the metacenter, $M$. Tu produce a particular angle of attack, the center of gravity should lie along the force line. The vehicle must be able to restore 1 tself if a correction of angle of attack is required. A thange in angle of attack w1ll produce a change in the center of pressure, and consequently a change in the force ine. This new force line will produce a moment in the restoring direction is long as the rate of change of $Y_{C p}$ with respect to u (cilled the stability derivative, and defined as $y$ ) remalng suffictently large and negative. The maximus angle of attack up to which $\gamma$ maintalns this condition will be referred to as izmax. The force IIne at $\alpha_{\max }$ will therefore be the upper IImft for the location of the center of gravity. The longltudinal location for the center of gravity is bounded by $X_{c p}$ and $M$ of this same force line. The quantitles $r, \alpha_{\max }$, and $M$ therefore completely determine the stability characteristlis of a vehtcle and will be referred to frequentiy in the next section.

The code was written In FURTRAN for a DEC VAX/VMS system, and the average run timc for i complete case was under $2 \mathrm{mln}$. 
$\underline{\text { Results }}$

Aerobraking Vehtcles

The aerodynamic characteristics computed for one case of a typlcal symetric body are first described. Several parameters are then varled to provide Information for generating an optimum body shape. All the data are normalized with respect to the maximum radius, $\mathbb{R}_{\max }$, of the body so that the results are presented in a comparable form for ench body shape.

\section{Symetrlc Body Shape}

A symetric body w1th rounded frustum is seen In F1g. 8, w1th $\theta_{f}=70^{\circ}, \theta_{a}=-70^{\circ}, R_{n}=0.6$, and $X_{s m}=0.24$. The $11 \mathrm{ft}$ and drag coeffictents and $L / D$ were computed for angles of attack between $0^{\circ}$ and $40^{\circ}$ and are shown in Figs. $9 a$ and $9 \mathrm{~b}$. A fore cone angle $>45^{\circ}$ w111 produce negative lift values; the absolute values will be used in this report. $C_{d}$ varted from 1.6 at $\alpha=5^{\circ}$ to 0.9 at $\alpha=40^{\circ}$, and $\left|c_{t}\right|$ varied between 0.1 and 0.5 for the same range. $|L / D|$ varied from a minlmum of 0.07 at $\alpha=5^{\circ}$, to a maximum of 0.57 at $\omega=40^{\circ}$. The varlation of the center of pressure $\left(X_{c p}, Y_{c p}\right)$ is seen in F1gs. $9 c$ and $9 d . X_{c p}$ remalned falrly constant at approximetely 0.41 up to $\alpha=30^{\circ}$, and then increased rapidly to 0.46 at $a=40^{\circ}$. $Y_{C p}$ decreased 11nearly up to $\alpha=30^{\circ}$ and then flattened out. In $F 1 \mathrm{~g} .9 \mathrm{e}, \mathrm{M}$ remained between 1.6 and 1.65 up to $\alpha=25^{\circ}$ and then decreased rapldiy. The stab1l1ty derivative also remalned falrly constant up to $25^{\circ}$ with a value of approximately 0.29; however, the decrease that is seen for $25<x<30$ Indicates that this is the maximum $\alpha$ for maintaining stability. From these results, the maximum angle of attack $\left(\alpha_{\text {max }}\right)$ for this body shape $1 \mathrm{~s}$ close to $25^{\circ}$. At $\alpha_{\max }$, $|\mathrm{L} / \mathrm{D}|=0.35$.

To assess the effect of change on the nose radius, cases were run for $R_{n} / R_{\max }$ varylng from 0.3 to 2.4 , with all other parameters unchanged. The results were quite slmilar to the case already described. F1gure 10a 11lustrates that although the stab1lity derivative was a maximum for $R_{n} / R_{\max }=1.0$, the overall change was not s1gnif1cant unt11 $R_{n} / R_{\max }>2.0$. P lotted on the same hraph is the variation $M$ with respect to $R_{n} / R_{\max }$ Inftially, $M$ also remalned falrly constant, then increased for the larger nose rad11. Both curves are only valid up to $\alpha_{\max }$. $|L / D|$ at $\alpha_{\max }$ varled very little, maintalning a value between 0.35 and 0.37 . These results indicate that the nose radius has iftle effect on the characterlsilcs of the body, although $\gamma$ does decrease for large values of $R_{n} / R_{\max }$.

Another body parameter of interest is the roundness of the frustum edge. The change in radius of curvature is controlled by $x_{s m} / R_{\max }$, the location where smoothing is to begin. The smoothIng width, $w=\left(\mathrm{X}_{c}-\mathrm{X}_{\mathrm{sm}}\right) / \mathrm{R}_{\max }$, is the distance between the cut line and $X_{s m}$, and as this decreases, the frustum edge becomes sharper, that 1s, the smallest $X_{s m}$ produces the most rounded edge. Th1s effect can be seen in F1g. $2 c$ where the suld Jine was produced by a greater smoothing willth than the dotted ine. Cases were run varying iv rrom 0.08 to 0.38 . The results of thds variation can be seen in Fig. 10b. As is Increased, $Y$ nlso Increased, Indlcating that the more rounded frustum edge produced a significantly more stable body. At the same t1me, $M$ decreased. This Implies that the more stable bodles have a smaller range for locating the center of gravity. The maximum angle of attack remaine: it $25^{\circ}$, whereas $|L / D|$ varied from 0.31 for the most rounded edge to 0.39 for the sharpest.

Increasing or decreasing the fore half conc angle, $\theta_{\mathrm{f}}$, had a signiflcant ef fect on the rangu of the stability derivative, and on the location of $M$. Cases were run for $\theta f=60^{\circ}$ and $80^{\circ}$ for comparison with the $70^{\circ}$ results above. It was difficult to match the body dimensions for true compartsons; nevertheless, a clear plcture emerged. Figure 11 shows some interesting results. With increasing $\theta_{\mathrm{f}}, M$ increased from 1.5 at $60^{\circ}$ to 2.25 at $80^{\circ}$ (F1g. 11a), whereas $Y$ decreased from 0.35 to 0.19 (Fig. 11b). Even more interesting, $a_{\max }$ Increased to $35^{\circ}$ for $\theta_{\ddagger}=60^{\circ}$ and decreased to a very low $15^{\circ}$ for the $80^{\circ}$ case. As a consequence, $|\mathrm{L} / \mathrm{D}|$ at $a_{\max } 1 \mathrm{~s}$ greatest for the $60^{\circ}$ case (F1g. 1ic). The range of $|L / D|$ was more dependent on the body shape than on the other variables; Fig. $11 \mathrm{c}$ also indicates the range of $|\mathrm{L} / \mathrm{D}|$ for each cone angle.

These data show that the fore cone angle has a significant effect on the stablitity of the vehtcle. An angle of $70^{\circ}$ appears to be the opt 1 mum fore cone angle for this type of aerobraking vehlcle. A fore cone angle of $60^{\circ}$ restricts the location of the center of gravity to a falrly small range; however, it has a greater stablitty dertvative. For the $80^{\circ}$ case, $\alpha_{\max }=15^{\circ}$ would almost certalniy be too low.

\section{Asymetric Body Shape}

The characteristics of axially asymetric bodles were also examined in this work. Figure 12 is a profile of such an asymetric body with $\theta_{f}=70^{\circ}, \theta_{a}=-70^{\circ}, \theta_{b}=5^{\circ}, R_{n}=0.96$, and $x_{5 m}=0.26$. Because of asymetry, the character1stics were evaluated for angles of attack bet :en $-40^{\circ}$ and $+40^{\circ}$. The values computed for $C_{d},\left|C_{L}\right|$, and $|L / D|$ were very close to the values for the simllarly proportioned symetric case. The $M$ for each force line no longer lies on the long1tudinal axis as this is not the symmetric axis of the body. In this figure, $M$ lies above the longltudinal axis at a point where most of the force IInes meet. This is at a value approximately equal to 1.6. Figure 13 is a plot of $\gamma$ versus angle of attack. Between $-25<a<25$, the stabillty derivative remalned falrly constant at a value $\equiv 0.28$, again indicating an $\alpha_{\max } \cong 25^{\circ}$.

To find the effect of changing the bend angle, the same case was run for $\theta_{b}=3^{\circ}, 7^{\circ}$, and $10^{\circ}$. When the stabllity derfvatives were compared with the $5^{\circ}$ case, very little change had occurred; $\gamma$ remained between 0.27 and 0.28 . The $M$ slightly Increased with increasing bend angle. This indicates that the bend angle can probably be chosen to best suit the other requirements of the vehicle, particularly for maintaining 1 ts roll stability. The amount of bend angle required for this roll stab1lity needs further 1nvestigation.

The effect of a fore cone angle change was also Investigated, and, as in the symetric case, exact comparisons could not be made. However, the same general plcture was produccl: The larger 
cone angle of $60^{\circ}$ generated a larger stab1l1ty derivative and a smaller $M$. The range for $\alpha_{\text {max }}$ agaln ran from $35^{\circ}$ for $\theta_{E}=60^{\circ}$ to $15^{\circ}$ for $0_{f}=80^{\circ}$.

In conclusion, the 1ntroduction of a small bend angle to a symetric aerobraking vehtcle will have little effect on the longltudinal stability.

\section{Aeromaneuvering Velitcle}

The concept of creating a h1gh lift, high $\mathrm{L} / \mathrm{D}$ vehicle by truncating a bent biconic body was introduced earlier in this report. This truncated body is the lower segment of the intersection of a second order equation with a bent biconic body. The equation is defined by three given points on this upper surface. An example 1s shown in F1g. 14, where the shaded portion is the truncated body. The finallzed body shape. must fulfill several requirements. These arc:

1) The body should bo proportloned for ut1lizIng the cargo bay of the Space Slutetle (approximately 20 by $5 \mathrm{~m}$ ) as efficiently as posstble.

2) The rear side area must be large enough to produce yaw and roll stability.

3) The under surface must be sufficlently curved to produce longltudinal stabllity.

With these constraints in mind, the chosen body shape, seen In F1g. 15, was determined by trial and error. The blconic surface was generated from a body with $\theta_{f}=10^{\circ}, \theta_{a}=10^{\circ}, \theta_{b}=5^{\circ}, x_{s m}=0.4$, and $X_{c}-0.6$. The three points defining the upper surface equation were $(0.3-0.05)$, $(0.6-0.095)$, and $(1.0-0.13)$. The three vlews of the body seen In F1g. 15 are plotted to the same scale. The lower curved surface can be seen with the greatest volume in the rear (F1g. 15a). It 1s clear that the sharp leading edges will require some form of active coollng. The upper dotted portion, which indicates the dead air region at $\alpha=0$, can be filled without affecting the aerodynamlc characteristics. This dead alr region would increase when the vehicle flles at a finite angle of attack. Also shown are the force lines for $5^{\circ}<a<30^{\circ}$. Flgure $15 \mathrm{~b}$ is the view from above, showing a large area on the upper surface, and $\mathrm{Flg}$. $15 \mathrm{c}$ is the view from the front, showing the area profected on the $\mathrm{y}-\mathrm{z}$ plane. F1gure 16 detalls the aerodynamic characteristics computed for this aeromaneuvering vehicle. In F1g. 16a, the range of $I . / D$ is from 7.2 at zero angle of attack to 1.4 at $\alpha=30^{\circ}$. A sufficlent spread in $X_{c p}$ 1s required to provide the required atablilty margin. The computed values of $X_{c p}$ presented in F1g. 16b indicates a sufficient sprending up to an $a_{\max }$ approximately equal to $20^{\circ}$. At this amax, $L / D$ still maintains a value of 2.0 .

The volume to carry fuel and cargo must be found within the dead-air region on the lee side of the vehicle. The actual cargo-carrying volume will be determined by the intended maximum $L / D$ : the higher this $I / D$, the smaller the angle of at tack, leading to a smaller cargo volume. Eventually, the cargo-carrying volume will be so small that the vehfcle will. be unable to carry all of 1 ts own fuel Internally. Additional fuel could be provided by external fuel tanke. Figure 17 indlcates how the vehicla and two fuel canks could efflciently utilize the Space Shuttle cargo bay. Finally, a sequence of events is proposed for the vehicle to perform its journey from the Space Shutele to another orblting body. These steps, shown in Fig. 18, are:

1) The vehicle is deployed from the Shuttle cargo bay, with the external fuel tanks attachech.

2) The rocket engines ignite and the vehicle begins Its fourney toward the Earth's atmosphere.

3) The empty fuel tanks are jettisoned and the vehicle enters the atmosphere.

4) Using 1ts designed maneuvering capabilites, the vehicle banks and turns into i.ts ncw orbit.

5) The vehicle exits the atmosphere and rendezvous with a satellite.

Because of the large $L / D$ of this vehicle, the required amount of fuel for perfurming aeromaneuvering will be quite small. It may even be possible to make two plane changes in one misstun, thereby enabling the vehicle to reach its destinitIon and return to the Space Shuttle.

\section{Conc1usions}

Symetric and asymmetrlc aerobraking bodles and an aeromaneuvering body can be generated by generallzed bent biconic geometry. The aerodynamic characteristics derived for these bodies using Newtonlan flow theory were shown to be sufficlently accurate for preliminary design studles.

For aerobraking bodies, a $70^{\circ}$ half cone angle prov1ded the best compromise between longitudinal stability and center of gravity location. The introduction of a small asymetry to a symetric body had little effect on the aerodynamic characterlstics. For an aeromaneuvering vehicle, it is possible to design a body that has an $I / D>2$ and which can still maintain a positive stability margin.

\section{References}

${ }^{1}$ Walberg, G. D., "A Review of Aeroassisted Orb1t Transfer," AIAA Paper 82-1378, Aug. 1982.

${ }^{2}$ Schmitt, D. A., "Base heating on an Aerobraking Orbital Transfer Vehicle," AIAA Paper 83-0408, Jan. 1983.

${ }^{3}$ Florence, D. E., "Aerothermodynamic Design Feasib1lity of a Generic Planetary Aerocapture/ Aeromaneuver Vehfcle," AIAA Paper 81-1127. June 1981.

Miller, C. G., Blackstock, T. A., Helms, V. T., and Midden, R. E., "An Experfmental Investigation of Control Surface Effectiveness and Rea1-Gas Simulation for Biconics," AIAA Paper 83-0213, Jan. 1983.

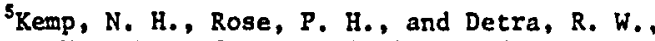
"Laminar Heat Transfer Around Blunt Bodies in D1sassoclated A1r," Journal of Aeronautles and Space: Sclences, Vol. 26, No. 7, July 1959, pp. 
${ }^{6}$ Swaminathir, S., K1m, M. D., and Lewls, C. H., "Three-Dimensional Nonequilibrium Vlscous ShockLayer Flows over Complex Geomerrics," hIAA

Paper 83-0212, Jan. 1983.

7Andrews, D. G., Caluor1, V. A., and

Bloetscher, F.. "Optimization of Aerobraked Orbital

Transfer Vehicles," AIAA Paper 81-1126, June 1981.
BHayes, D. W. and Probste1n, R. F., "Hypersonic Flow Theory," Applied Mathematics and Mochenics, Vol. 5, Academic Press, 1959, p. 73.

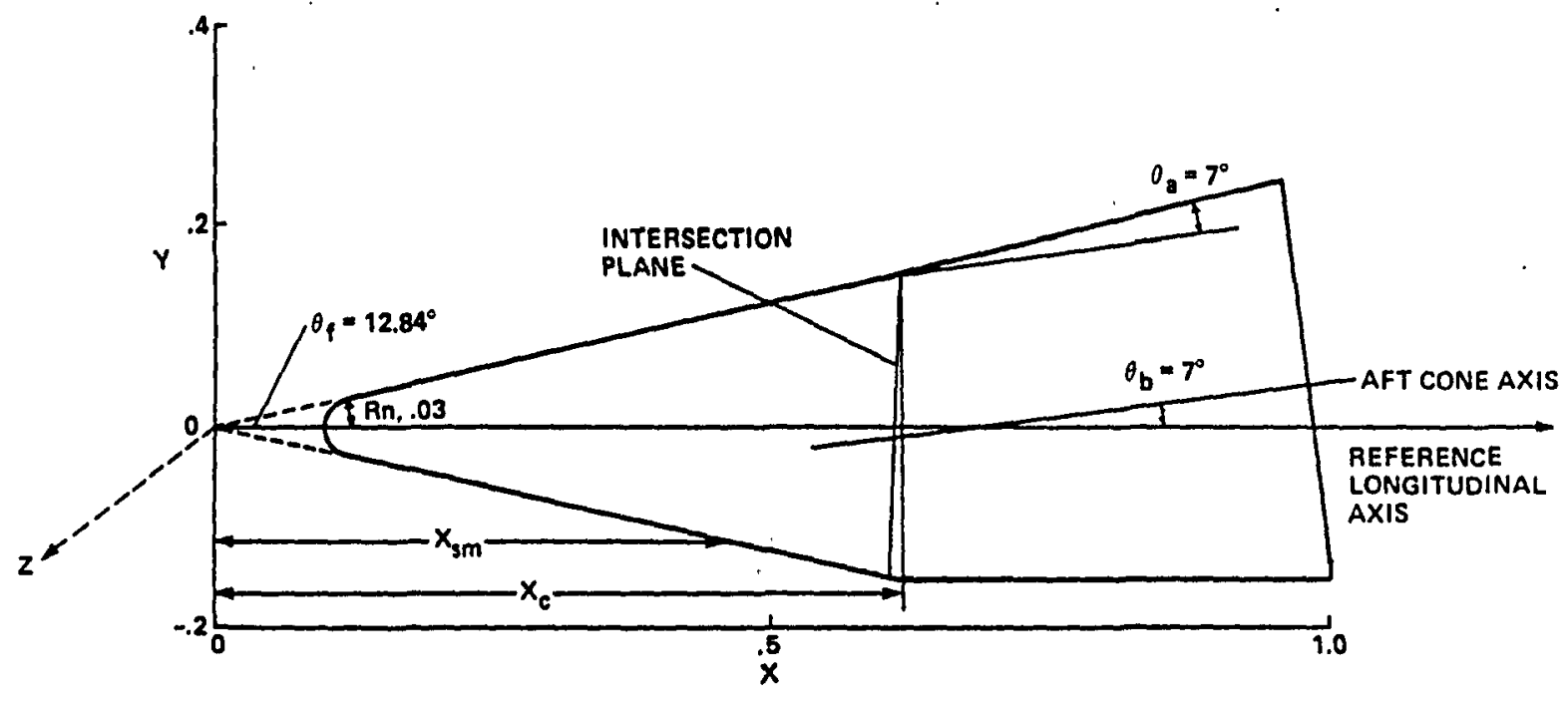

Hg. 1 Bent BIconic with $\theta_{f}=12.84^{\circ}, \theta_{a}=7^{\circ}, \theta_{b}=7^{\circ}, R_{n}=0.03$, and $x_{c}=0.6$. 


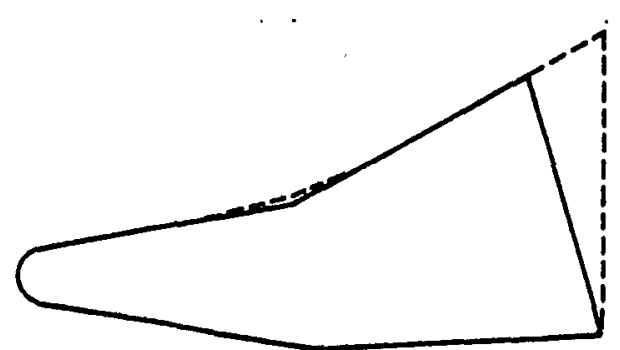

(a) SMOOTHING AND END BODY TRUNCATION

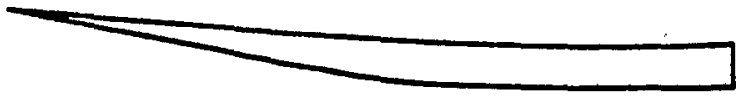

(b) TRUNCATION OF UPPER BODY

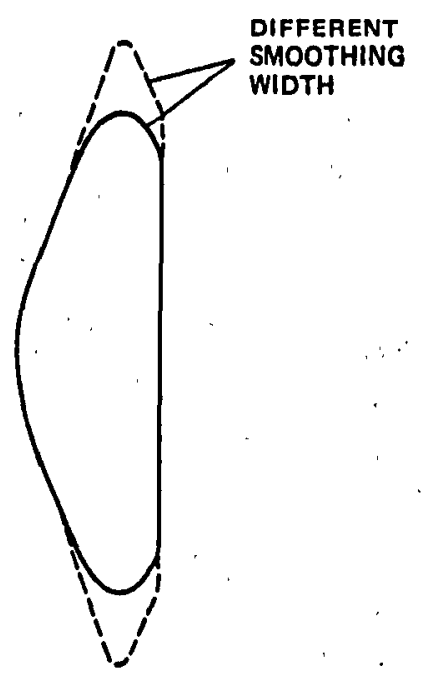

(c) SYMMETRIC BODY WITH LARGE $R_{n}$ AND NEGATIVE AFT CONE

Fig. 2 Generallzed, bent biconic body shapes.

(a) Optional smoothing and end body truncation;

(b) Truncation of upper body; (c) Symmetric body

with large $R_{n}$ and negative aft cone angle;

(d) Asymmetric body, finfte bend angle.

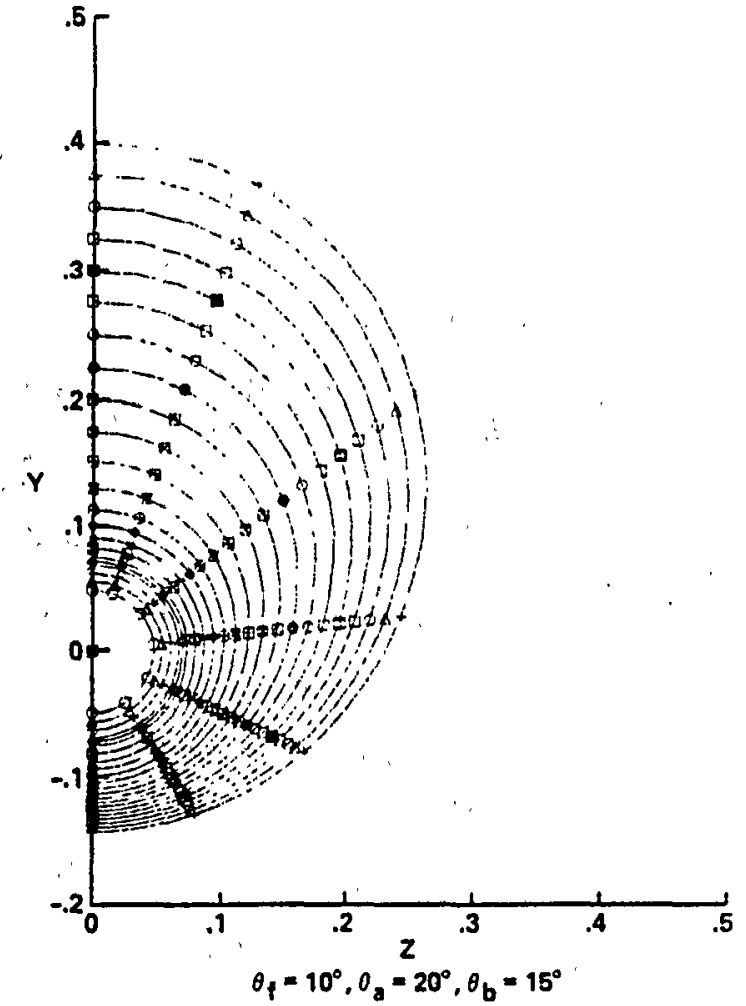

F18. 3 Cross section of bent biconic with $\theta_{f}=10^{\circ}, \theta_{a}=20^{\circ}, \theta_{b}=15^{\circ}$. 

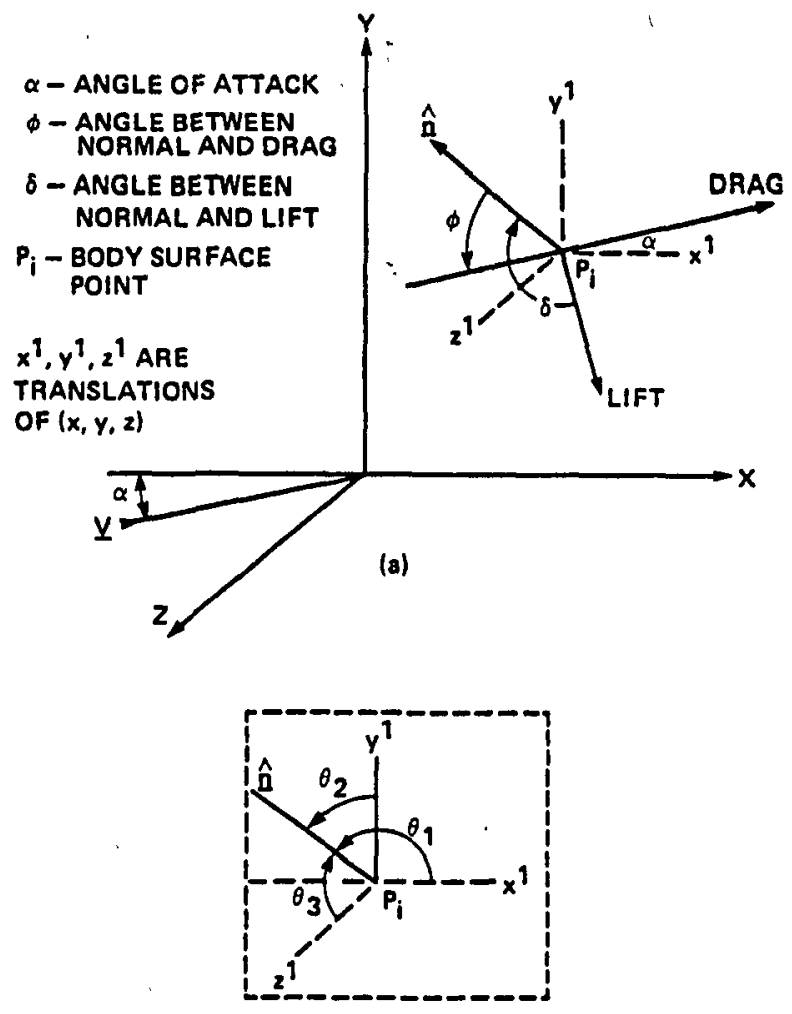

DIRECTION COSINES OF BODY
NORMAL AT SURFACE POINT P;
$\hat{\mathbf{n}}-\cos \theta_{\mathfrak{j}}+\cos \theta_{2} \mathfrak{j}+\cos \theta_{3} \hat{k}$

(b)

F1g. 4 Lift and drag forces at body surface point $P$.

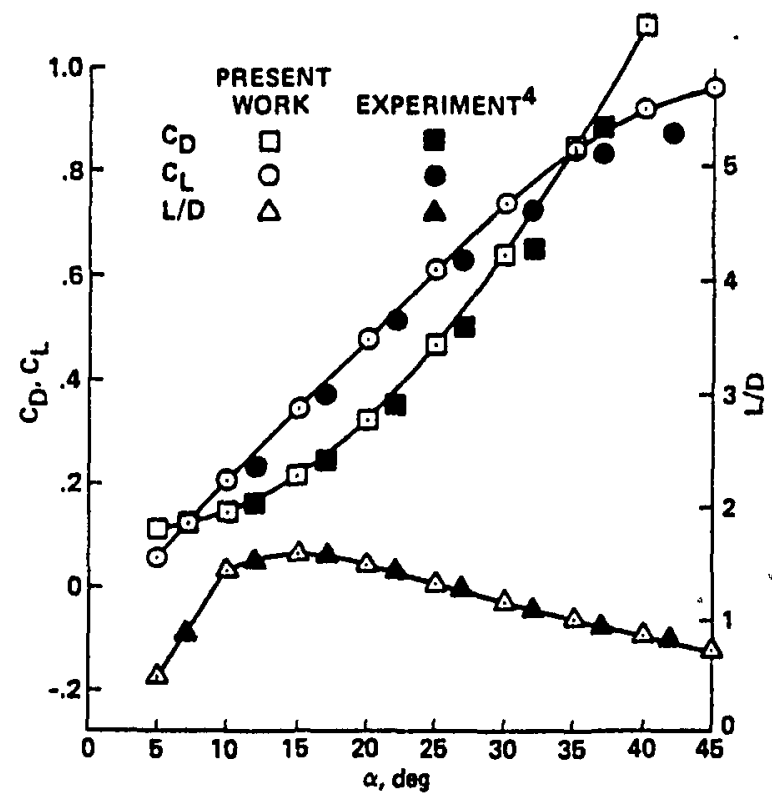

Flg. 5 Comparison of lift and drag coefficlents and $L / D$ with experimental results for body seen in Fig. 1.

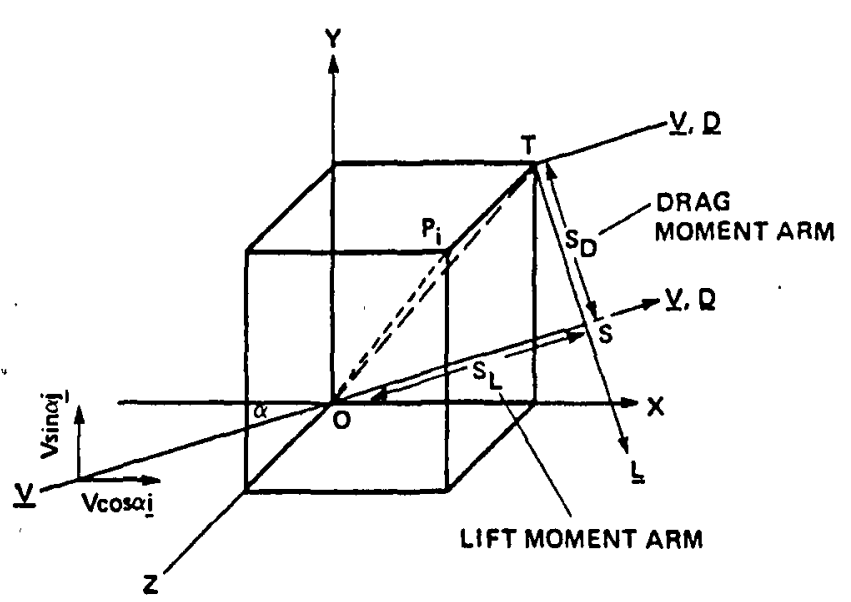

F1g. 6 Computation of moments; or is the projection of $O P$ onto the $x-y$ plane. 


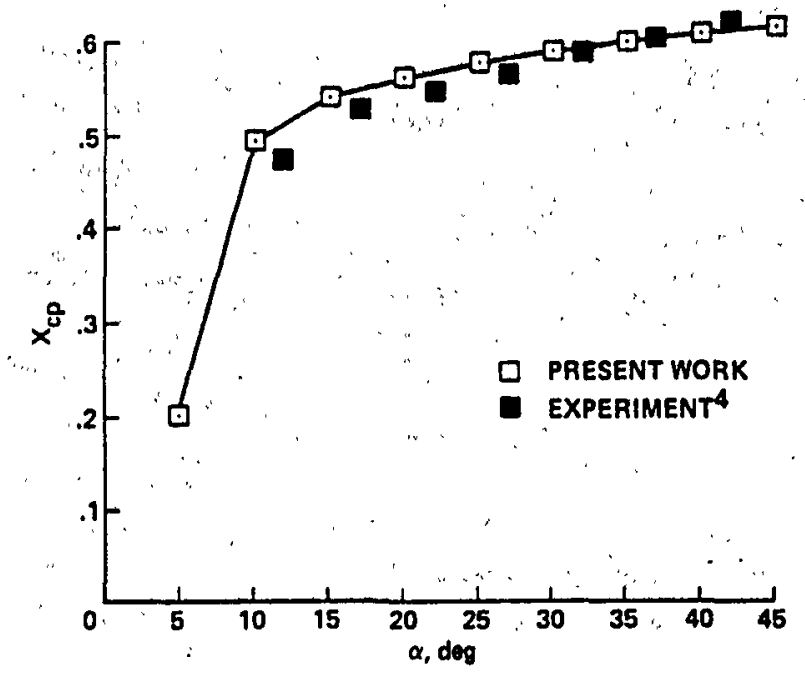

F1g. 7 Comparison of calculated center of pressure with experimental data for body seen In F18. 1 .

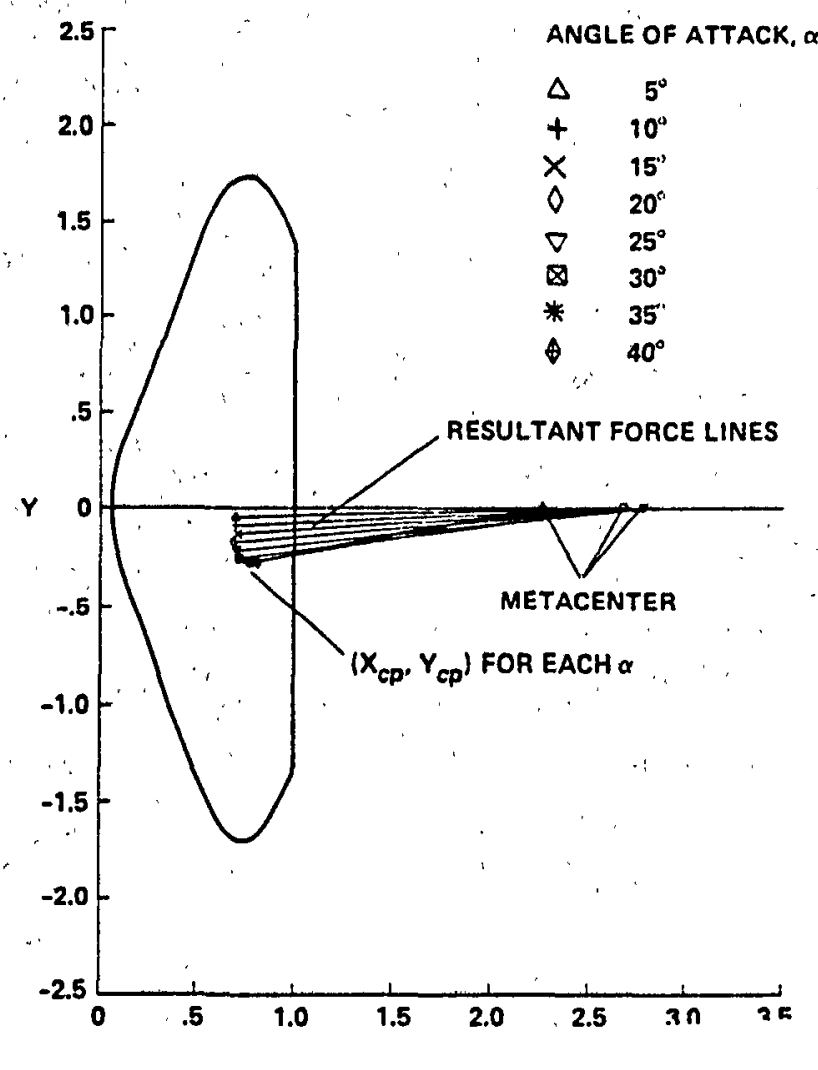

F1g. 8 Symmetric aerobraking body with $\theta_{\mathfrak{f}}=70^{\circ}$, $R_{n} / R_{\max }=0.6, x_{s m} / R_{\max }=0.24$. 

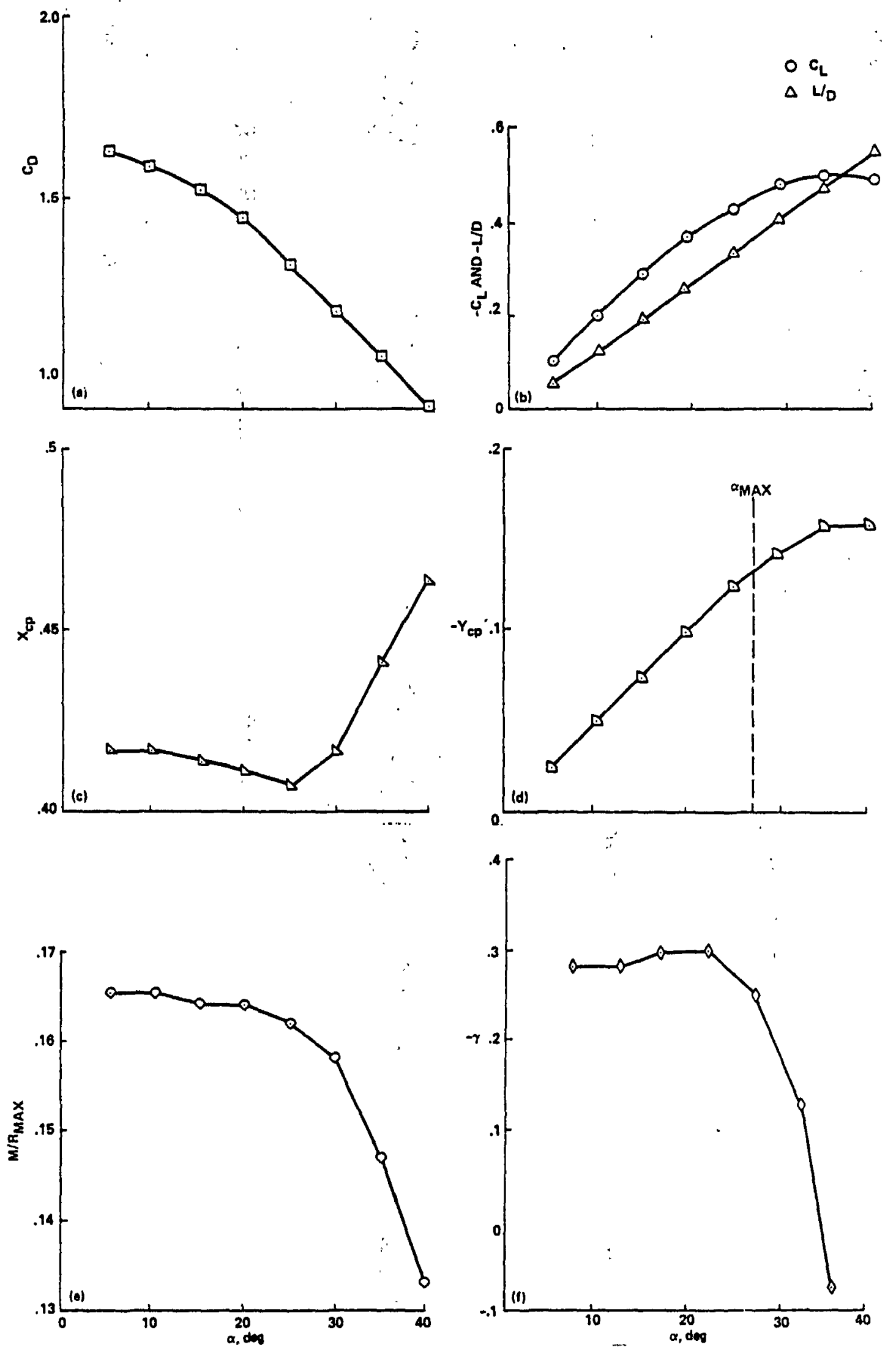

Fis. 9 Aerodynamic characteristics of body in Fig. 8 . 


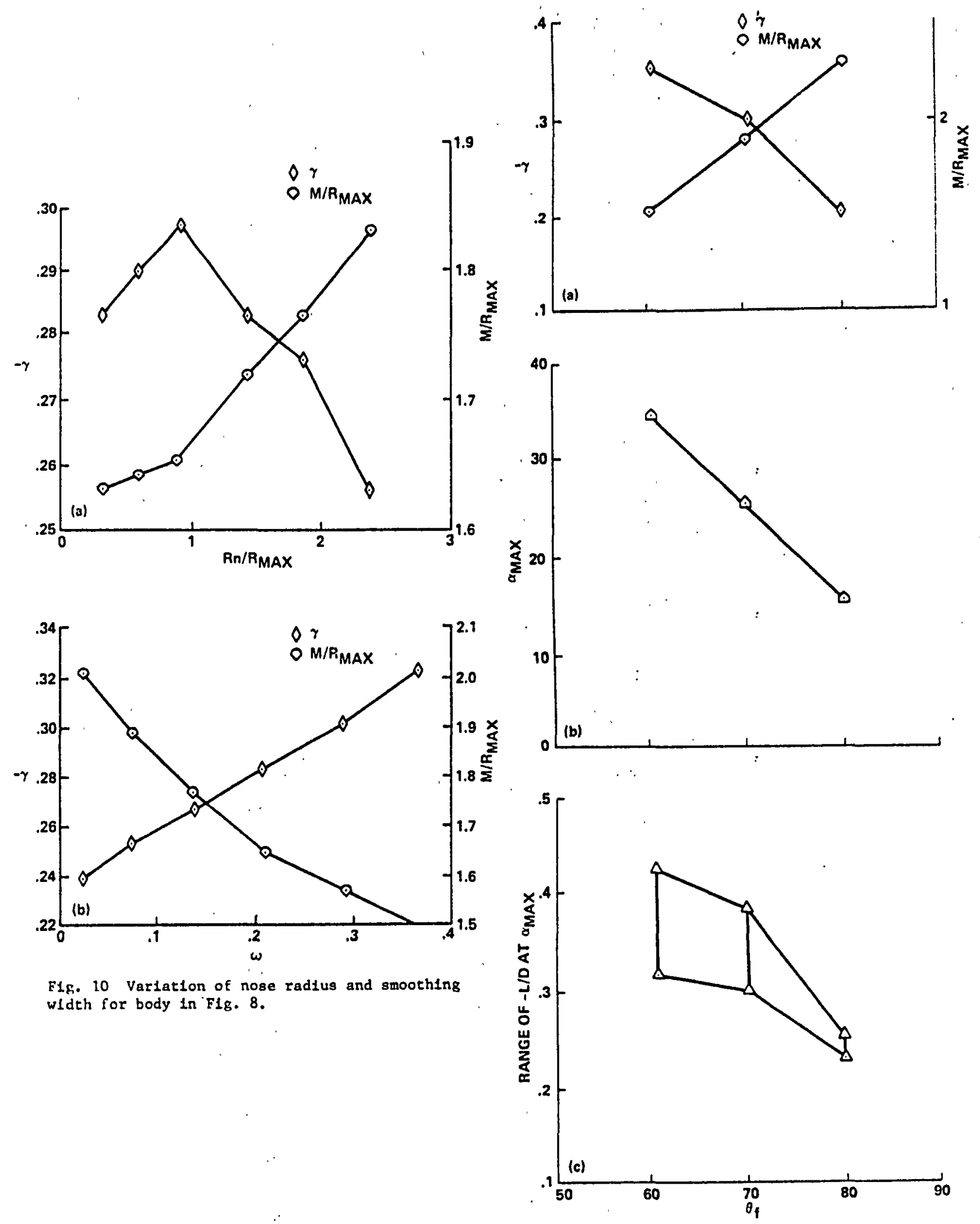

F1g. 11 Effect of change In half cone angle for symmetric bodies. 


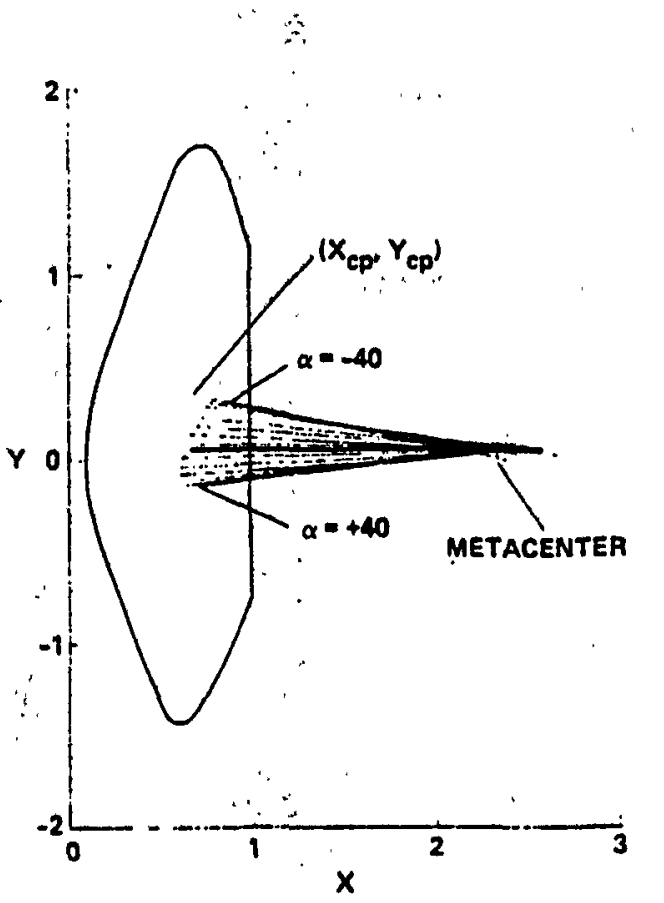

F1g. 12 Aaymetric body with $\theta_{f}=70^{\circ}, \theta_{b}=5^{\circ}$, $R_{n}=0.96, X_{8 \pi t}=0.26$ (showlng the lines of force).

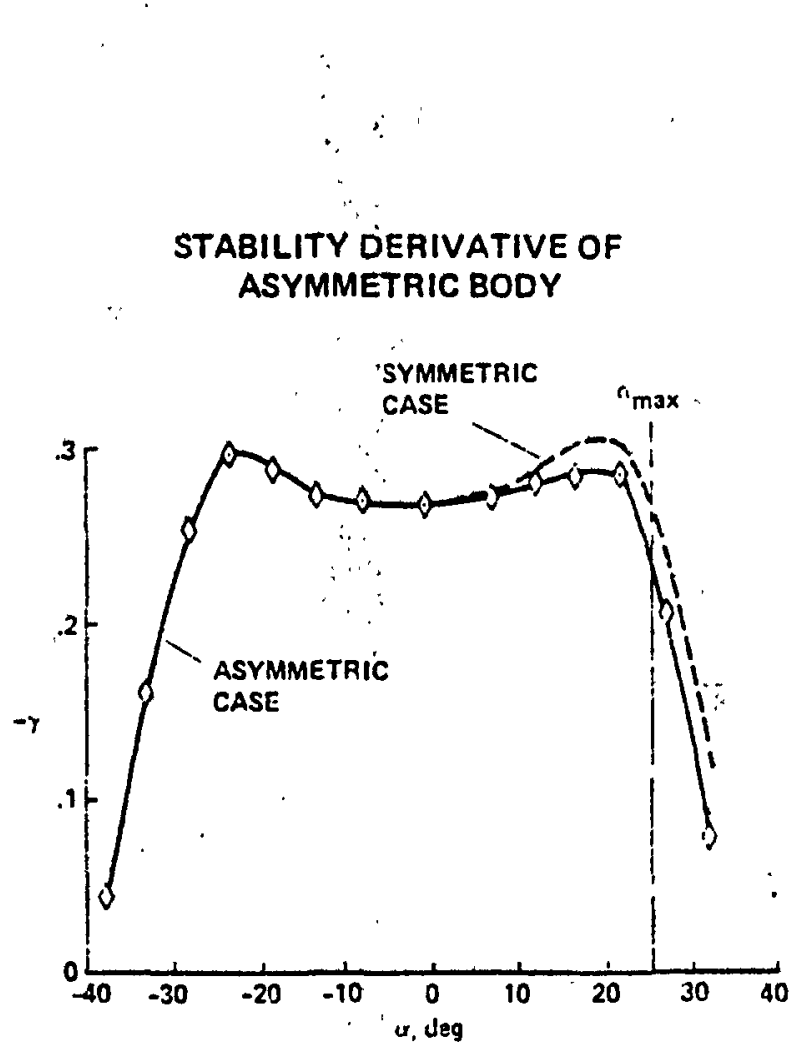

F1g. 13 Stabllity derivative for body in F1g. 12. 


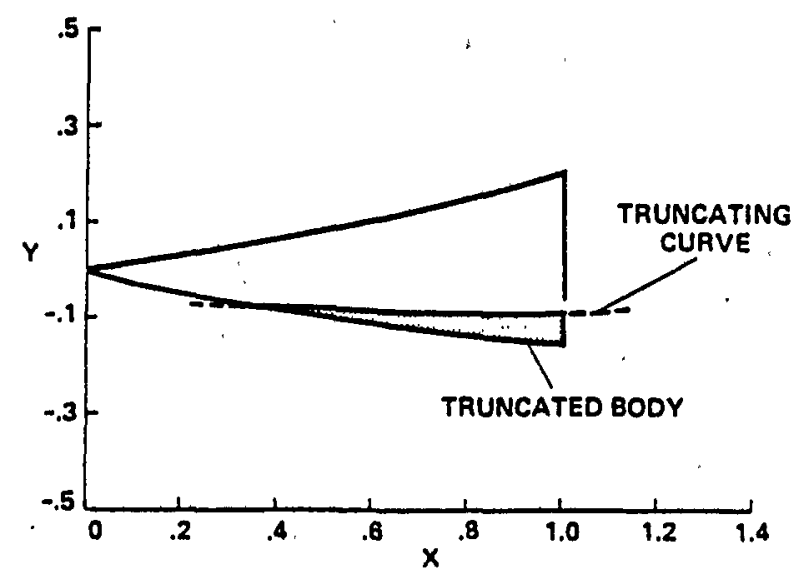

F1g. 14 Truncated portion of a bent biconic with

$\theta_{f}=10^{\circ}, \theta_{a}=10^{\circ}, \theta_{b}=5^{\circ}, x_{c}=0.7, x_{s m}=0.4$.

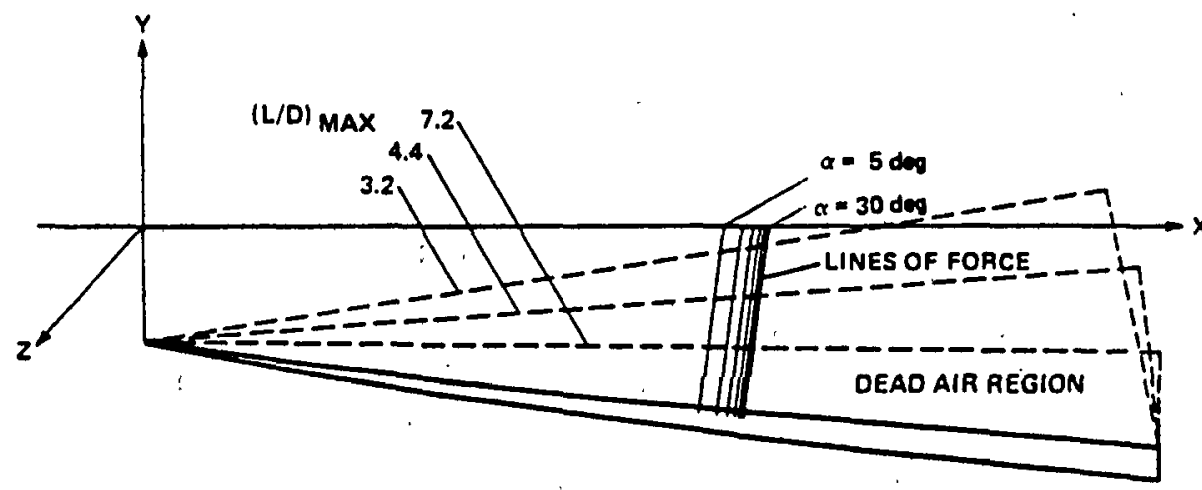

(a) SIDE VIEW

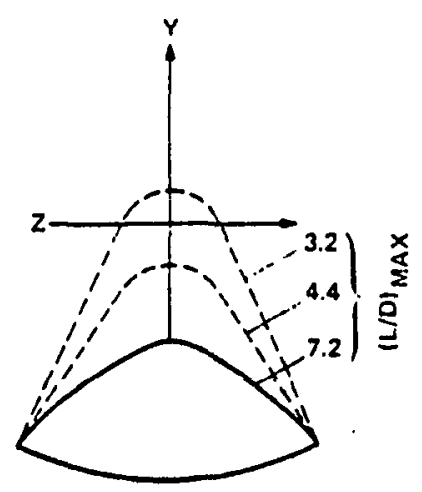

(c) FRONT VIEW

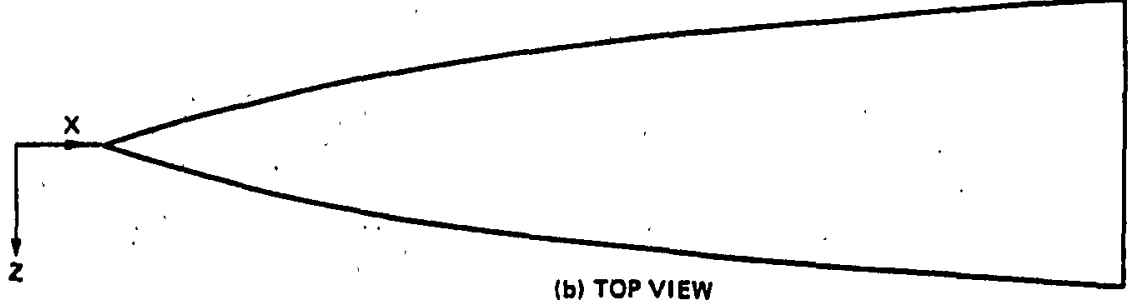

F1g. 15 Three views of an aeromaneuvering vehtcle. 

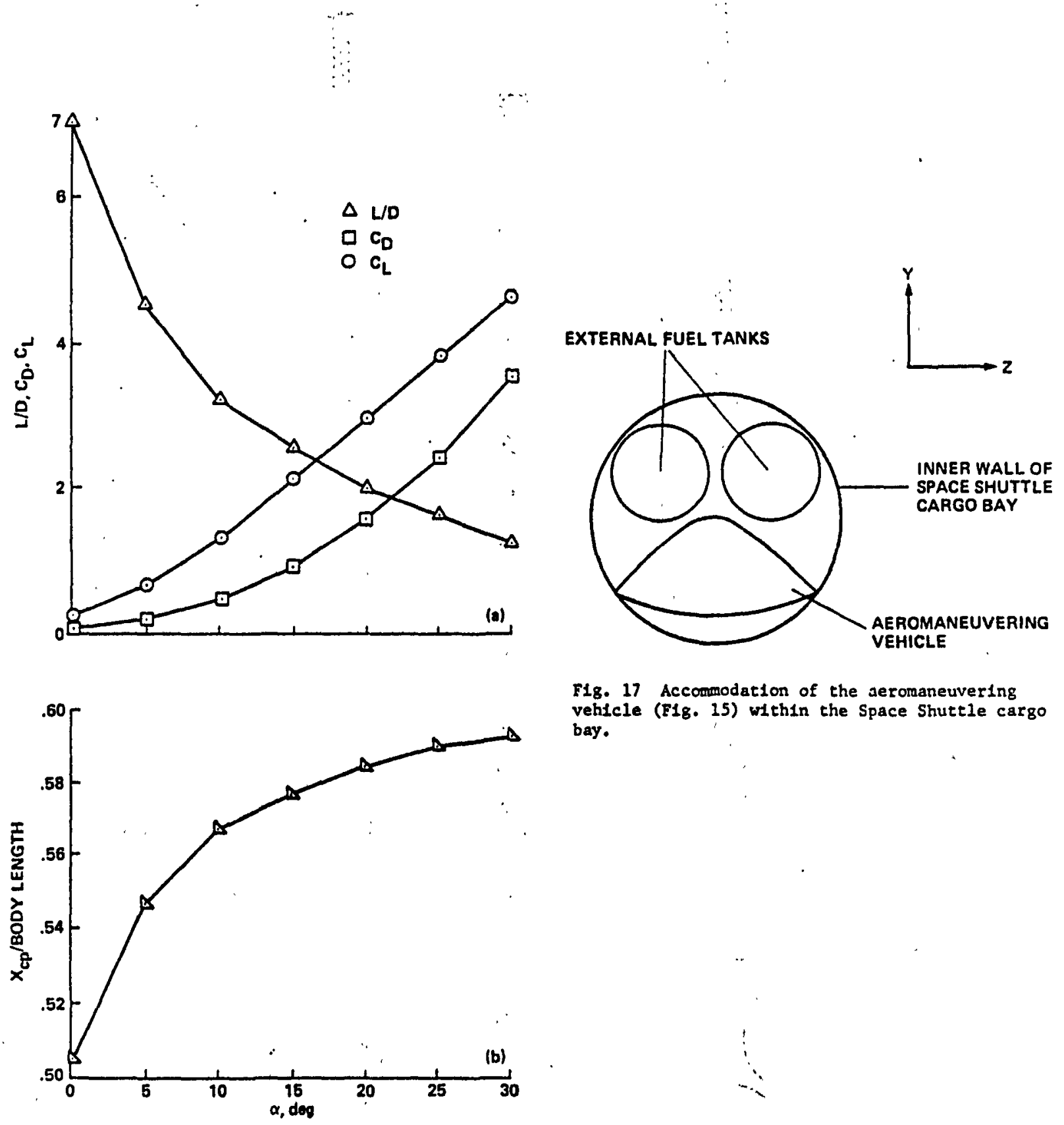

F18. 17 Accomodation of the deromaneuvering vehicle (F1g. 15) within the Space Shuttle cargo bay.

F18. 16 Aerodynamic characterist1cs for truncated body shown in F18. 15 . 

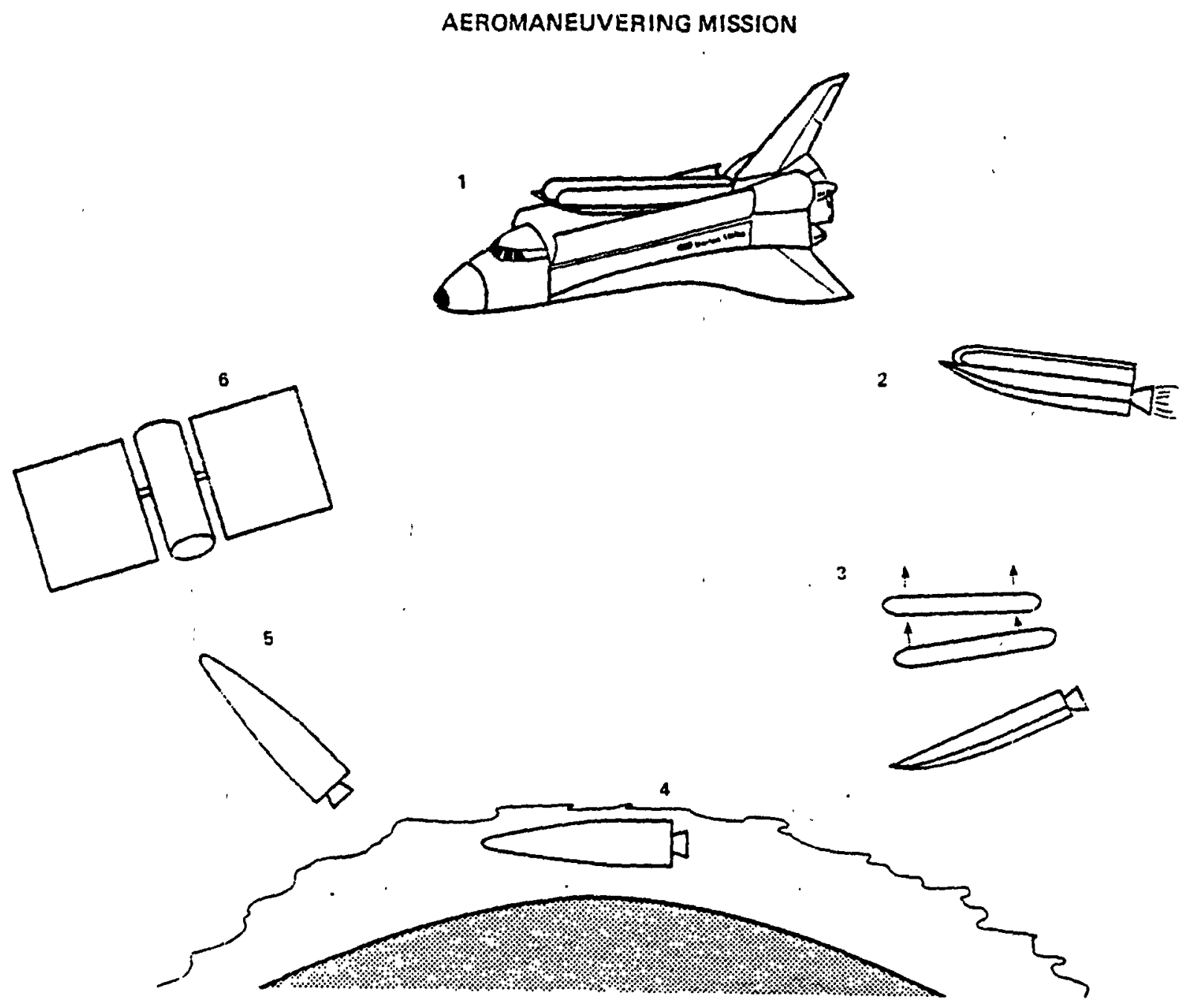


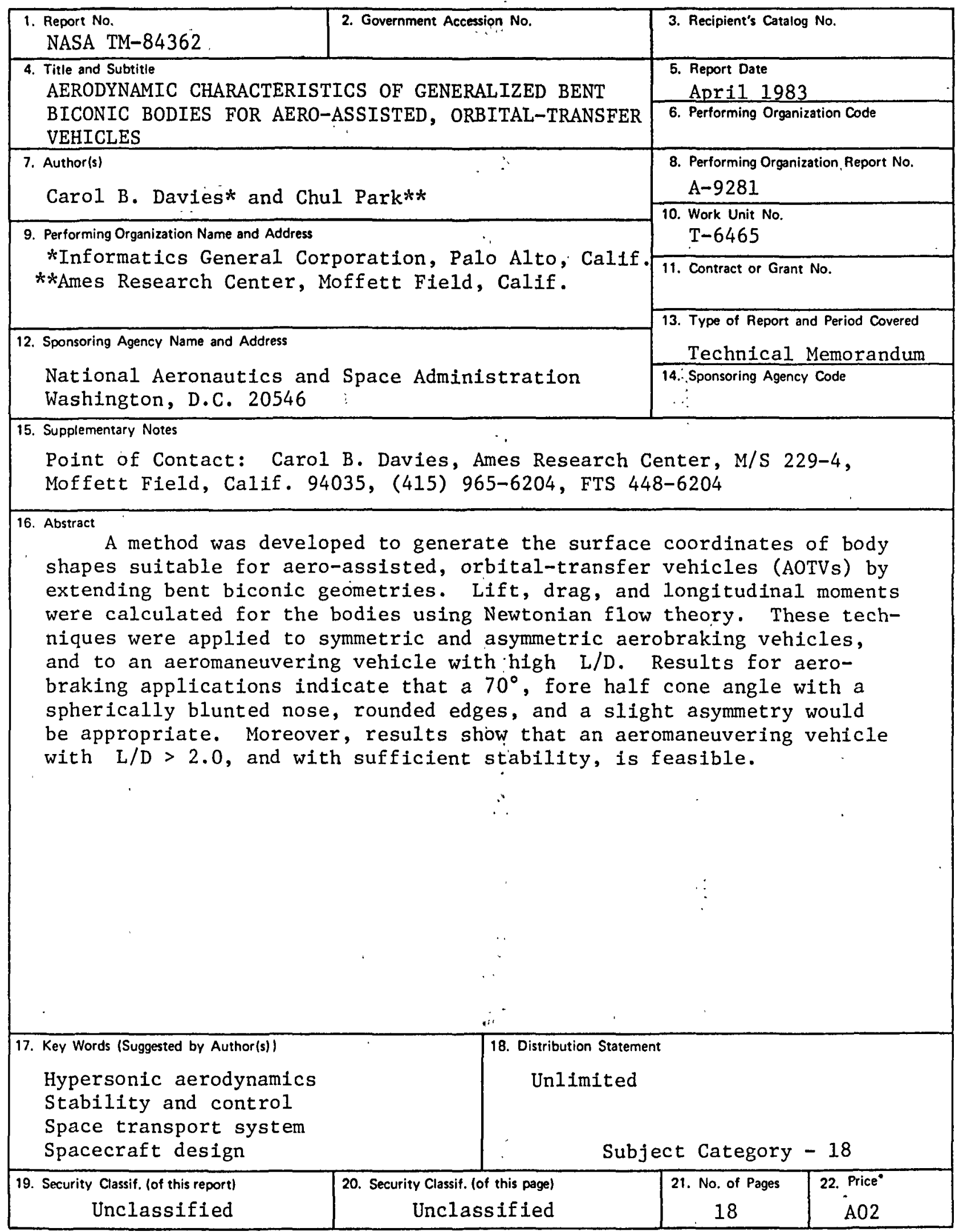

-For sale by the National Terhrical Information Service, Springfield, Virginia 22161 